\title{
Land Use Change Detection and Impact Assessment on an Agricultural Area
}

\author{
Beatrice Tarimo ${ }^{1}$, Elifuraha Mtalo $^{2}$ \& Evaristo Liwa ${ }^{1}$ \\ ${ }^{1}$ School of Geospatial Sciences and Technology, Ardhi University, Dar Es Salaam, Tanzania \\ ${ }^{2}$ University of Bagamoyo, Bagamoyo, Tanzania \\ Correspondence: Evaristo Liwa, School of Geospatial Sciences and Technology, P. O. Box 35176 Dar Es \\ Salaam Tanzania. Tel: 255-22-2775248.E-mail: liwa@aru.ac.tz; everistliwa@gmail.com
}

Received: April 10, 2013 Accepted: September 23, 2013 Online Published: October 12, 2013

doi:10.5539/jsd.v6n11p55 URL: http://dx.doi.org/10.5539/jsd.v6n11p55

\begin{abstract}
This study focuses on detecting, mapping and analyzing the conversion of forests into agricultural uses and agricultural uses into urban/peri-urban uses in Nzega district, Tabora Region - Tanzania over a period of 28 years since 1978. Land use classes were from multitemporal and multi-sensor satellite images and aerial photographs. Topographical maps at a scale of 1:50000 and onsite information gathered in the field were used for interpretation and ground truthing purposes. Land use changes were detected using land use change matrices and land use change maps. Four land use maps were compiled from Aerial photographs dated 1978, Landsat TM satellite imagery dated 1986, Landsat ETM+ satellite imagery dated 2000 and IRS satellite imagery dated 2006. The maps show agricultural areas are concentrated along road networks generally expanding towards neighboring grasslands and unprotected forested areas. Land use changes were detected from land use maps for three change periods: 1978 - 1986, 1986 - 2000 and 2000 - 2006, with emphasis on agricultural and forest land uses. The change maps and change matrices show that despite abandoned farms agricultural land increases with time. Change in the opposite direction was also common where abandoned agricultural land gradually regenerated back to grasslands and forests. An average of $16 \%$ of agricultural land has been maintained during the 1978 - 2006 period compared to $67 \%$ of forests that have been maintained in the same period of time.
\end{abstract}

Keywords: land use, land use change, agricultural area

\section{Introduction}

The dynamics in land use changes are brought about by a number of interacting factors including socio-economic, political, cultural and environmental factors (Lambin, Geist, \& Lepers, 2003) and have prominent effects on the balance of ecosystems and on human productivity and welfare (Mertens, \& Lambin, 1999; Srivastava, Han, Rico-Ramirez, Bray, \& Islam, 2012). The control, management and prediction of future trends in environmental change, natural resources and food security are among the issues that require detailed information on land use and its changes over different spatial extents.

Tanzania has $80 \%$ of its population living in rural areas (Mbwambo, 2004) their main occupation being agricultural activities. Tanzania's fast growing population has led to higher and varied consumption demands, that in turn cause major changes in the use of land and natural resources to meet these demands (Mbwambo, 2004; PPU, 2007). The changes are reflected in the growing number and size of settlements (PPU, 2005), deforestation (FOSA, 2000), decline in agricultural productivity (Amani, 2005) and environmental degradation (Hubacek \& Sun, 2001). To be able to control and manage land use change, systematic monitoring and mapping of change over spatial and temporal spaces is required to provide an understanding of the factors contributing to change and the role and significance of each of these factors.

The nature, amount and distribution of land use changes in Tanzania are not well known. There are several reports at National level (Kalenzi, 2006) documenting the occurrence of land use patterns and changes in the use of land resources but these reports mostly consist of non spatial information. Moreover, many existing reports are a result of studies conducted in the attempt to characterize global/regional environmental changes (Tunner, Moss, \& Skole, 1993), thus lacking detailed information of what is actually happening on extents smaller than the national level. 
The technique used to detect and map land use especially by land use planners in Tanzania are archaic and unsystematic and cannot determine accurately the rate, amount and extents of land use changes. Typically the approach used in Tanzania for land use mapping involves allocation of different land use zones to different land areas based on their natural characteristics e.g. soil and vegetation cover. With this approach, actual land uses and respective changes cannot be detected and mapped accurately neither can the temporal changes in land use be tracked on a regular basis. This study intends to map actual land uses and detect changes with emphasis on forests and agricultural land using existing remote sensing techniques. To monitor and control land use and land use changes at any spatial scale, an understanding of the trends in the use of land in a specified spatial extent over a given temporal span is required. We seek information on the trend of land use changes in agricultural and forested areas of Nzega District over a period of 28 years. There is also a need to assess the impacts of land use changes on agricultural areas as it is observed that agricultural land use undergo more changes in a given time (Xiaojian, Jim, Gang-Jung, \& Lexiang, 2000; Mertens, \& Lambin, 1999) than other land uses.

The dynamics in agricultural land use change and forest cover change are of interest due to their impacts on human beings and their environment. The main objective of this study is, therefore, to detect, map and analyze the conversion of forests into agricultural uses and agricultural uses into urban/peri-urban uses that have been taking place in the period 1978 to 2006 using available maps, aerial photographs and satellite images.

\section{Description of the Study Area}

Tabora Region is the largest region of Tanzania covering about 76,151 square kilometers which is approximately $9 \%$ of Tanzania. The region was previously subdivided into four districts namely Tabora, Urambo, Nzega and Igunga, later two other districts namely Uyui and Sikonge were established. The location of the present six districts in the region is shown in Figure 1.

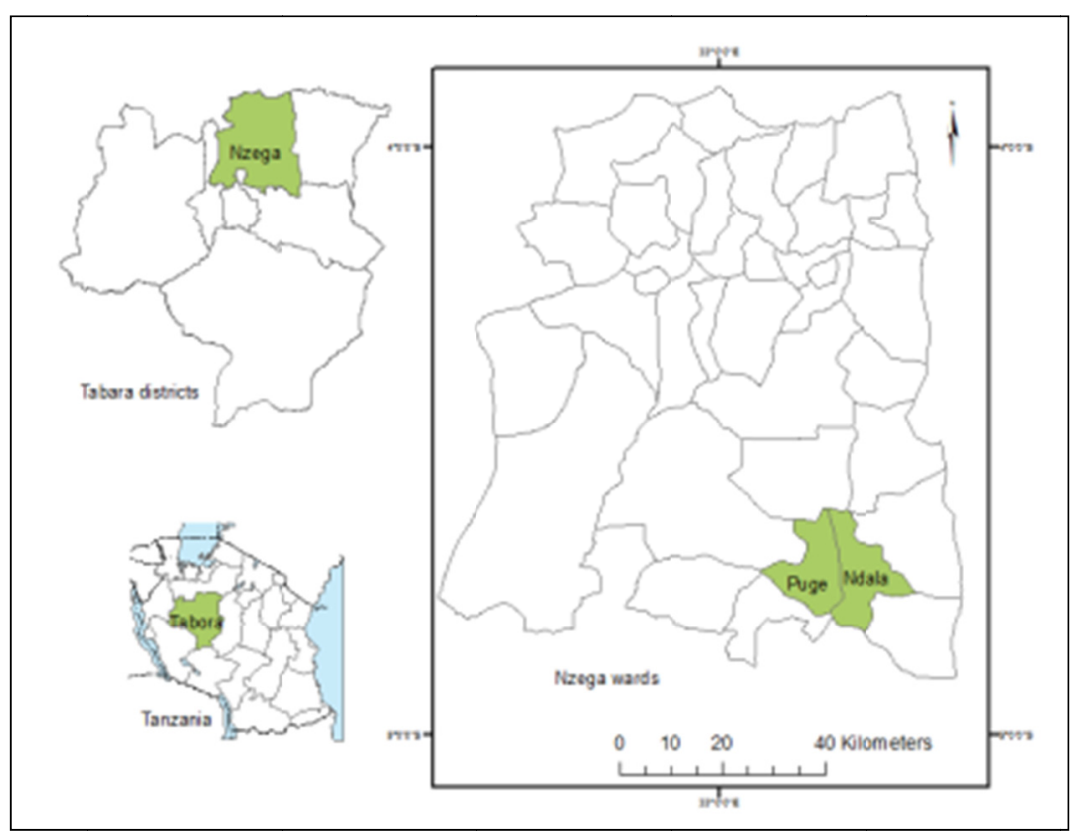

Figure 1. Map of Tabora showing the study area

The region is a plateau with altitude ranging between 1000 and $1500 \mathrm{~m}$ above mean sea level. It is the most forested region in the country composed of a number of forest reserves with varying spatial extents, game reserves and other natural forests which are not part of the reserves. Tabora forests are home to a variety of wildlife and insects. Some of the important vegetation includes miombo woodland, miombo-combretum woodland, combretum woodland, acacia woodland, bushland, deciduous woodland, thicket, grassland, swampy grassland and farmland (TRIDEP, 1980). A number of varieties of tree species exist summing up to about 170 types (TRIDEP, 1980).

Tabora region experiences a warm mild climate with temperatures ranging between $17{ }^{\circ} \mathrm{C}$ and $29^{\circ} \mathrm{C}$ and rainfall averaging between 650 and $1000 \mathrm{~mm}$ from November to April with the western part of the region receiving 
more rain than the eastern part of the region. In general the region experiences a high level of scarcity of water during the dry season.

The study area was chosen mainly based on availability of IRS satellite image then on agricultural activities, forested areas and dynamics in population demographics.

\section{Methods}

\subsection{Data Sources and Characteristics}

Data sources were determined based on the objectives of the study (Table 1 and Figure 2). Some of the constraints encountered are lack of cloud free data in the case of satellite imagery and lack of complete coverage in the case of aerial photographs. Landsat- 5 satellite images used in this study were obtained from the Centre for Information and Communication Technology (CICT) at Ardhi University. The IRS-P6 satellite images were kindly donated by Dr Rao of the IRS. Topographical maps and aerial photographs were bought from the Survey and Mapping Division (SMD) of the Ministry of Lands, Housing and Settlements Development (MLHSD).

\subsubsection{Aerial Photographs Data Characteristics}

The latest set of aerial photographs covering the area of study was taken during the Tabora Region Integrated Development Plan (TRIDEP) project in 1978 at a scale of 1:25000. Thirteen photographic paper prints were used during this wok. The photographs cover the area around Puge ward centre, along the road from Puge to Ndala and some areas around Ndala ward.

\subsubsection{Landsat Satellite Images}

Both Landsat TM and Landsat ETM+ satellite data were used. Landsat TM image was acquired during the dry season while landsat ETM+ image was acquired during the wet season.

\subsubsection{The IRS Data Characteristics}

The study made use of IRS-P6 satellite images as the principal source of data for the identification and characterization of current land use patterns in the area of study. IRS-P6, also known as Resourcesat-1, carries three cameras namely LISS-3, A WiFS and LISS-4 whose datasets were used in this study. IRS image was acquired during the wet season.

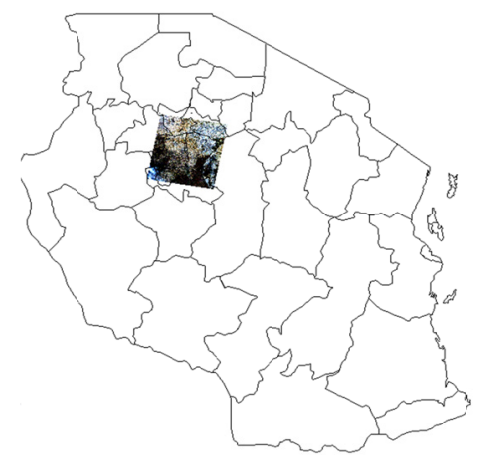

(a) Landsat TM's extent

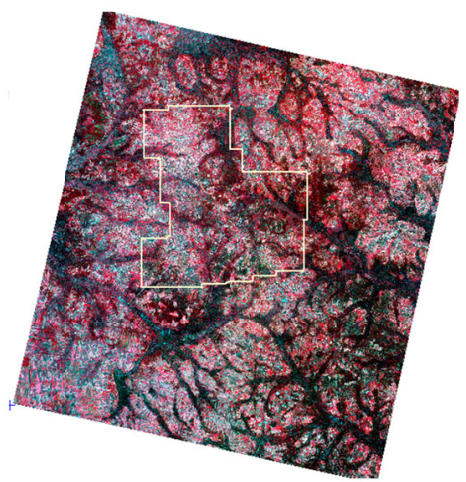

(c) Extent of Aerial photos in IRS

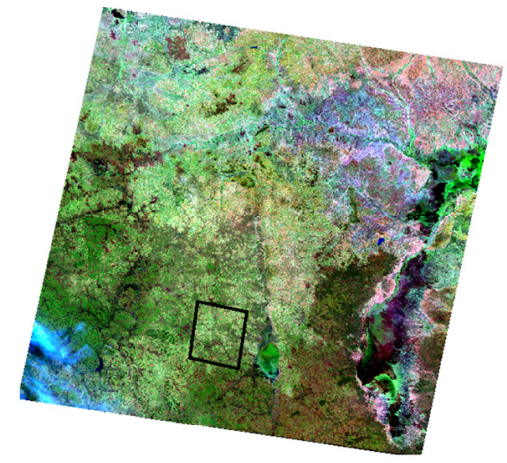

(b) IRS's extent in Landsat

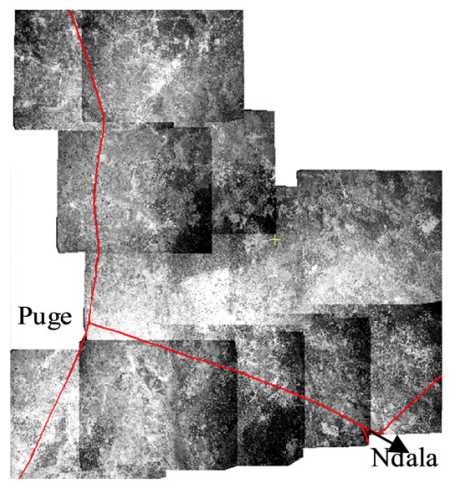

(d) Aerial photos

Figure 2. Types of data used in this study 
Table 1 . Summary of data characteristics

\begin{tabular}{lllll}
\hline Dataset & Date & Spatial resolution/Scale & Seasonality & Land cover/use extraction \\
\hline IRS & 2006 & $5 \mathrm{~m}$ & Wet & Maximum likelihood Classification \\
Landsat ETM+ & 2000 & $30 \mathrm{~m}$ & Wet & Maximum likelihood Classification \\
Landsat TM & 1986 & $30 \mathrm{~m}$ & Dry & Maximum likelihood Classification \\
Aerial photos & 1978 & $1: 25000$ & & Visual interpretation and Digitization \\
\hline
\end{tabular}

\subsubsection{Ground Truthing Data}

A field trip was carried out with the aim of gathering ground truth information for purposes of image classification. Ground truthing refers to the process of collecting field information to be used for training supervised classification and for accuracy assessment of classification results. Garmin EMTAC S3 BTGPS hand held GPS receiver hosted by a pocket PC was used to collect GPS position of points representing land use and cover classes of interest and routes of interest that were traversed. Ground truthing was performed in 2007 during the wet season similar to acquisition of IRS and Landsat ETM satellite images.

\subsubsection{Unstructured Interviews}

Some useful information was acquired through unstructured interviews of key informants at Puge Division's local Government. Two interviews were conducted at Puge division Local Government's office on $8^{\text {th }}$ and $9^{\text {th }}$ February, 2007. Each was done based on unstructured questionnaires prepared prior to the field visit as guidelines to the interviews. Two people namely the Puge Division's Secretary General and the Agricultural and Veterinary Officer, were interviewed.

\subsection{Data Validation}

Validation for topographical maps and aerial photographs consisted of examination of features present in the paper maps and the paper prints using distance measurements and by visual inspection. Both the topographical maps and aerial photographs were found to be in good order for the purpose of this study; the quality was good enough to allow interpretation of features both visually and digitally. The information present in topographical maps tallied with the corresponding information in aerial photographs; assuring consistency. Prominent features present on the ground were confirmed by visual observation to be in place in the topographical maps and aerial photographs implying that topographical maps and aerial photographs used in this study still form a reliable source of information despite the fact that they are outdated.

The quality of satellite images from both IRS and Landsat was checked by examining consistency with topographical maps and aerial photographs and found to conform to the requirements of this study. Both satellite image data were $100 \%$ cloud free within the study area although IRS and Landsat ETM+ imagery were acquired during the rainy season.

\subsection{Data Processing}

Data sets acquired were pre-processed to fit the requirements of this study. Satellite data sets used were preprocessed at Level - 2 preprocessing, where radiometric correction and systematic geometric correction were performed. However some deviations from the mapping system used in Tanzania, especially in the position of features (coordinates) were identified therefore the position of features in the satellite image were rectified to conform to those of the mapping system of Tanzania. Aerial photographs covering the area of study were scanned and used to create a controlled mosaic. Due to lack of ground photo control points the aerial photographs could not be processed photogrammetrically. Instead, the photographs were georeferenced using coordinates scaled from topographical maps and then land use patterns were extracted from the photographs through visual interpretation and digitization

\subsection{Image Classification}

Supervised classification was selected to make use of ancillary data in the classification process in order to achieve high accuracy. Training sites were developed using knowledge obtained from field data, topographical maps and information from people familiar with the area of study.

The method used for supervised classification was maximum likelihood classification which is based on both the distances towards class means and the variance-covariance matrix of each class. The method groups together 
features in specified classes based on the likelihood of each feature to the training set representing a specified class.

Interpreting land use from satellite images require additional information that can link land cover classes captured by satellite images to human related activities that represent land use classes (Kandrika \& Roy, 2008). Land use classes were inferred from land cover classes based on ground observations, visual patterns on both aerial photos and satellite images and ancillary information including local residents and expert experiences. Table 2 defines classes mapped. The main goal of image classification was to extract agricultural areas and the interaction between abandoned and newly acquired farms with other classes. Land cover classes were therefore categorized and grouped based on how they facilitate or limit changes in agricultural areas. Among the classes mapped agricultural land and peri-urban centers are referred to as land use classes while forests, woodlands, grasslands and marshlands are referred to as land cover classes.

Table 2. Description of lad use/cover classes mapped

\begin{tabular}{|c|c|}
\hline $\begin{array}{l}\text { Land use/cove } \\
\text { class }\end{array}$ & Description \\
\hline Agricultural land & Mixed farming - cultivation, animal keeping intermixed with scattered settlements \\
\hline Forests & Forested areas. Also include woodlands and shrubs when mapped from satellite images \\
\hline Grasslands & $\begin{array}{l}\text { Non-forested areas. Including abandoned farms, farms under fallow and unutilized land } \\
\text { areas }\end{array}$ \\
\hline Marshlands & Periodically inundated areas with shrubs and scattered trees \\
\hline Seasonal swamps & Swampy areas that may shrink during dry season \\
\hline
\end{tabular}

\subsection{Class Editing}

The results of classification show a high spectral overlap between some of the classes resulting into mixed classes. Some settlements, bare soil and roads were classified as one category as they all possessed similar spectral values. In areas where settlements are intermixed with agricultural land i.e. mixed farming, majority of the houses (Matembe) are thatched with dry grass or has packed soil as their roofing. Roads are not paved and spectrally resemble bare soil and/or unplanted farms. This made it difficult to distinguish between settlements, bare soil, farms and grasslands using the conventional multispectral image classification algorithms. Mixed classes were rectified through class editing, where each pixel in the mixed classes is visited and labeled by its true class. The true class of each pixel is identified by visually interpreting the satellite image data using available ground truth information. The approach is based on generating binary masks or bitmaps over areas where mixed classes are identified. The masks are then used to either restrict the classification algorithm to a spectral range of pixels representing respective classes in which case the image is reclassified using generated bitmap masks, or transfer pixels from one category to another, or merge classes that are to form one class or delete undesirable classes falling under the mask.

\subsection{Classification Accuracy Assessment}

The results of classification were assessed using error matrices. An error matrix compares classification results to additional ground truth information as a standard. The strength of an error matrix lies in the fact that it identifies the nature of classification errors, as well as their quantities (Lillesand, Kiefer, \& Chipman, 2004; Mather, 1999). Classification results were compared to ground truth data that was not used for training. Overall $80 \%$ and $77 \%$ was achieved for accuracy and reliability respectively. These results were influenced by peri-urban centers which had the least accuracy $(53 \%)$ and reliability $(56 \%)$; classes of interest namely forests, agricultural land and grasslands had better accuracy $(86 \%)$ and reliability $(89 \%)$.

\subsection{Land Use Change Detection}

This study made use of post classification comparison and GIS analysis of land use maps compiled from satellite images and aerial photographs to detect changes in land use categories. Classification results formed input to map calculation and overlay analysis functions where change maps and change matrices were generated. 


\section{Results and Discussion}

First, land use maps prepared from the datasets identified for this study are presented. Secondly land use change maps are presented emphasizing the changes occurring in forests and agricultural areas. Both land use maps and change maps are presented for the area common to all datasets which is the area covered by aerial photographs. Change maps together with change matrices show that agricultural land acreage is increasing year after year. It is also shown that changes occurring in forested and agricultural areas in the area of study are reversible such that some forests are being cleared for agricultural and other uses while part of the agricultural land is being abandoned gradually growing back into forests. Lastly the impacts of land use changes are also identified and presented.

Six land use classes namely agriculture, forests, grassland, marshland seasonal swamps and peri-urban centers were mapped from satellite images while six land cover classes namely agricultural areas, forests, woodland, shrubs, grassland and settlements were mapped from aerial photographs.

\subsection{Land Use Mapping}

Four land use maps were compiled from the four sets of data used namely Aerial photographs, Landsat TM satellite imagery, Landsat ETM+ satellite imagery and IRS satellite imagery.

\subsubsection{Land Use Map Compiled From Aerial Photographs}

Six land use classes were mapped from the aerial photographs (Figure 3). About $90 \%$ of the area was covered by forests, woodland, shrubs and grassland in the late 1970 s. The remaining $10 \%$ of the area was characterized by small patterns of agricultural land.

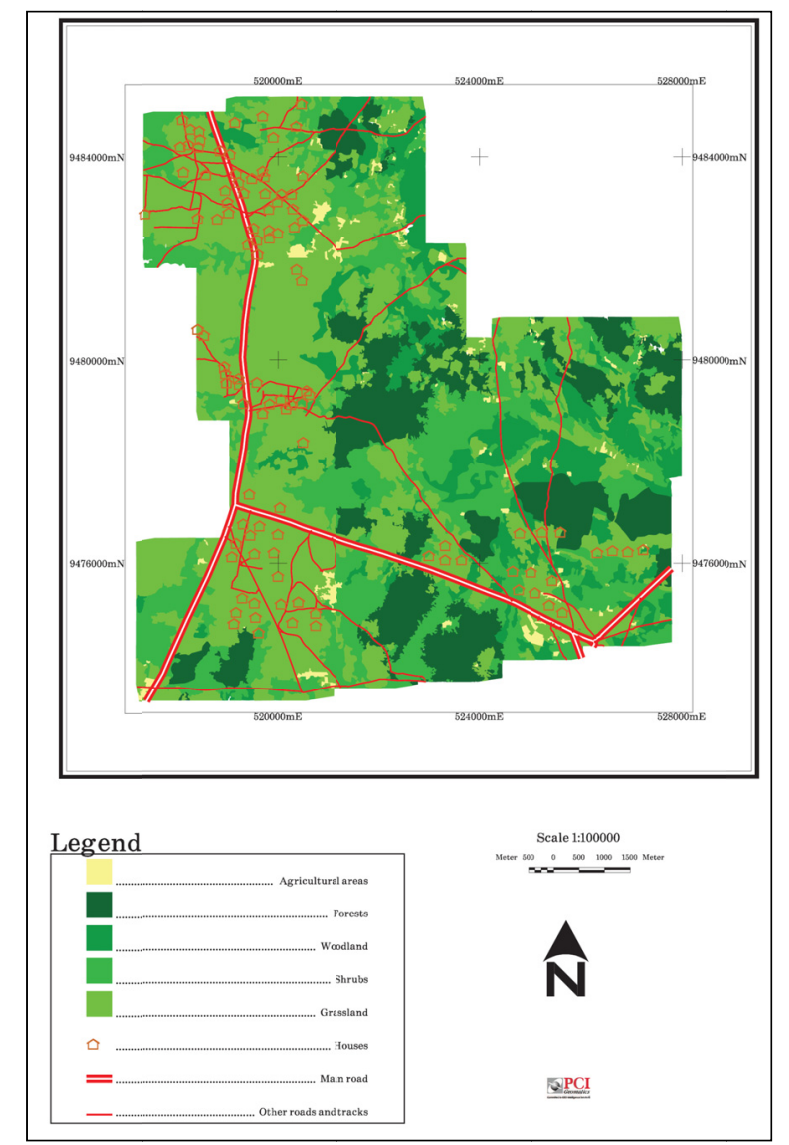

Figure 3. Land use map of Puge division compiled from 1978 aerial photographs

Agricultural areas were concentrated along road networks and in the neighborhood of settlement patterns. Most of the farms were adjacent to grasslands and shrubs while only few farms appear in the densely vegetated areas 
characterized by woodlands and forests. Farms were generally small during this period with a family farm of not more than one hectare.

Residential areas are categorized by clustered buildings along road networks forming small peri-urban centers and scattered settlements. Most of the scattered settlements are characterized by mixed farming i.e. farms intermixed with households where only few farms/grazing areas are located a distance away from the settlements. Grasslands occupy a fairly large area compared to woodlands and shrubs and occur mostly along road networks.

\subsubsection{Land Use Map Compiled From Landsat TM Satellite Image}

Six land use classes were mapped from Landsat TM satellite imagery (Figure 4). For the two classes of marshland, marshland (dried) represents the dried areas of marshland over continued dry season while marshland (wet) represents marshland areas still wet in the dry season.

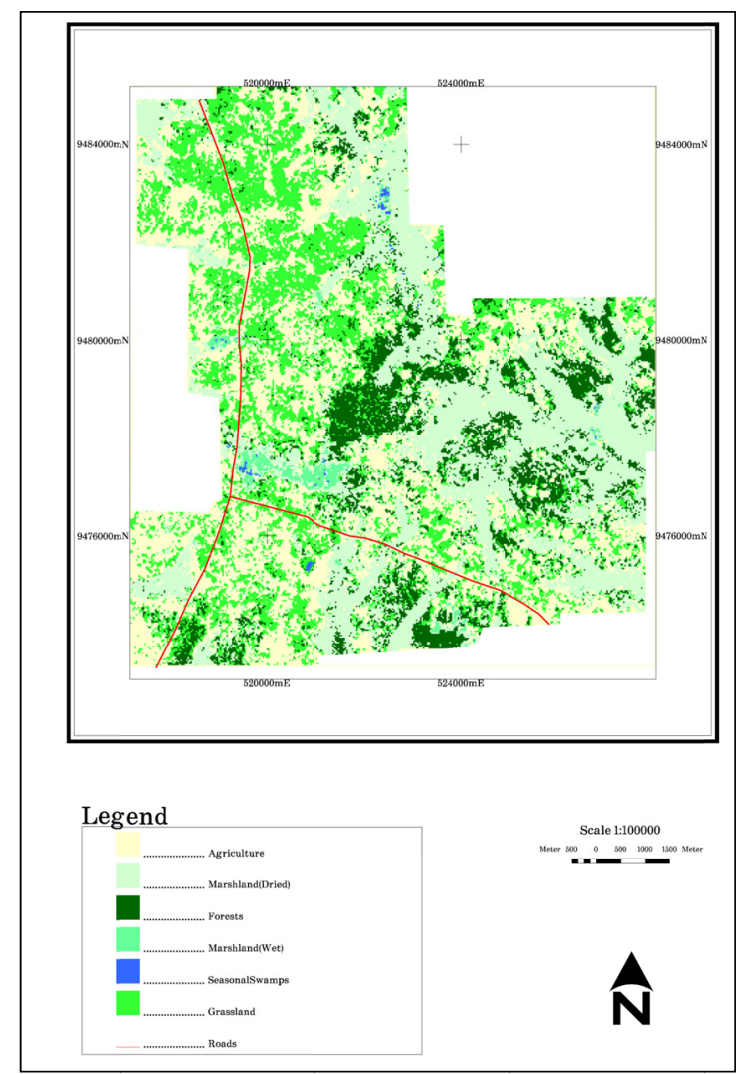

Figure 4. Land use map of Puge division compiled from 1986 Landsat TM satellite imagery

The difference in data characteristics between the land use map compiled from aerial photographs (late 1970's) and the one compiled from Landsat TM satellite imagery (mid 1980's) contribute to the observed difference in features mapped within different spatial extents in the area. Generally, forests are observed to occupy similar areas in both maps while areas mapped as shrubs and woodlands from aerial photographs were either mapped as marshland, grassland or agricultural land from Landsat TM satellite imagery.

Forested land acreage decreased by mid 1980's as compared to the late 1970's. This might be partly because of the seasonality of the image; being a dry season some of the forest particularly characterized by deciduous trees might have a decrease in their vegetative vigor thus less detectable spectrally in the satellite image. Some of the forests were also cleared for other uses especially agricultural activities which when abandoned developed into grasslands.

Agricultural land acreage increased during this period following the same patterns as the ones during the late 1970 's i.e. along road networks and adjacent to grasslands. The source of land for this increase is mainly from grasslands thus deforestation remained minimum. Population has also increased in the area (PPU, 2007) during 
this period thus agricultural areas (characterized by mixed farming) were expanded to accommodate increased population than increased production.

Grasslands still occupied a fairly large area despite the fact that some were converted for agricultural activities. They still form the major source of land for increased agricultural land acreage and the major recipient for the abandoned agricultural land. Moreover grasslands form part of the grazing land for the animals kept within the area.

\subsubsection{Land Use Map Compiled From Landsat ETM+ Imagery}

Five land use classes were mapped from Landsat ETM+ satellite imagery (Figure 5). Forest cover is observed to have significantly increased during this time i.e. in the year 2000 as compared to the late 1970s and mid 1980s represented in Figure 3 and 4 respectively. This might be partly due to the fact that the image was acquired during the wet season thus deciduous forests were more recognizable spectrally. Some of the areas covered by marshland (shrubs and scattered trees) in the mid 1980s are observed to have developed into forests in 2000. This might also be partly due to the seasonality of the image.

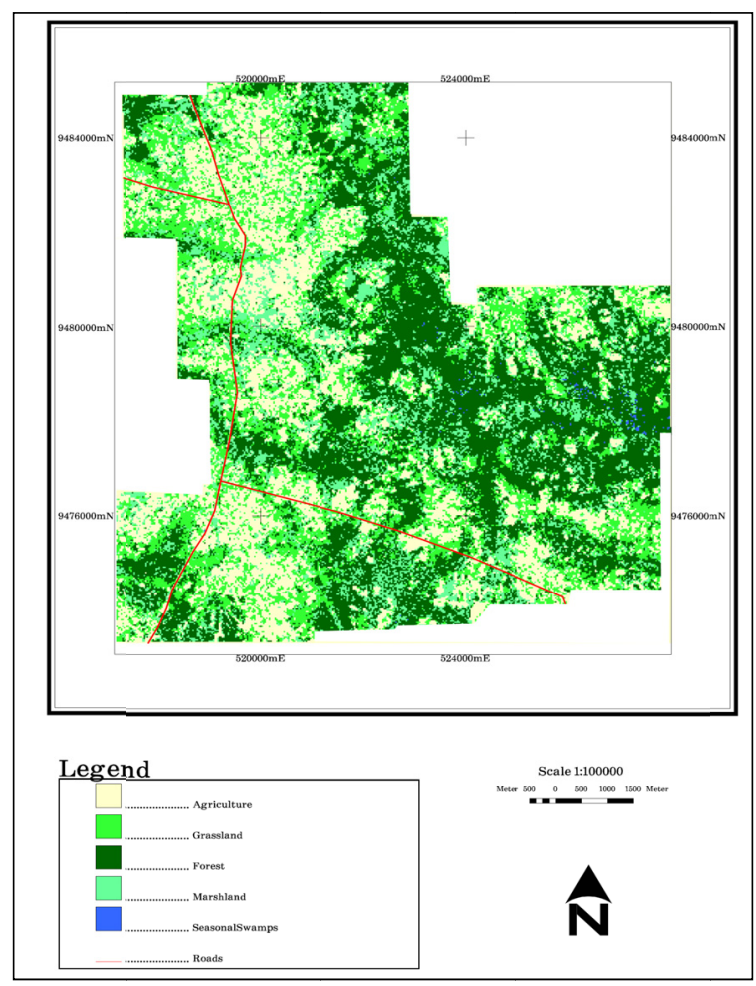

Figure 5. Land use map of Puge division compiled from 2000 Landsat ETM+ Satellite imagery

Agricultural areas maintained their sizes in this period as compared to the 1980s; with few areas experiencing changes from grassland to agricultural areas and vice versa. Agricultural activities were still characterized by mixed farming. Most of the farms were adjacent to grasslands as was also observed in the late 1970s and mid 1980s.

Some of the grasslands developed to marshland, the reason being the fact that the area is poorly drained and mainly water logged during heavy rains.

\subsubsection{Land Use Map Compiled From IRS Imagery}

Six land use classes were mapped from the IRS satellite imagery (Figure 6). The spatial resolution of the IRS satellite imagery facilitated mapping of peri-urban centers in this period.

Forests maintained their spatial coverage in 2006 relative to 2000 except for some few areas which were cleared for agricultural purposes. Agricultural land acreage significantly increased during this period following the same patterns as it was during the late 1970s and mid 1980s that is along road networks. The increase was due to policy implementation in which each family was directed to cultivate at least 5 hectares of land for both food 
security reasons and economic gain. The source of land for this increase in agricultural area is mainly from grassland and partly from forests. Agricultural activities in this period were also characterized by mixed farming. Grasslands continued to form an important source of land for agricultural expansion limiting the extent of forest clearance for the same. This is to say absence of grasslands in the future will result into further forest clearance for agricultural and residential uses in the absence of proper monitoring and management of the forests.

\subsection{Land Use/Cover Changes During 1978-2006 Period}

Land use changes were detected through post classification comparison and overlay of the satellite images and aerial photographs. Both digital change detection and GIS analysis were utilized. The results are land use change maps and land use change matrices showing spatial extents of land use changes and respective acreage in hectares. Changes within forests and agricultural land are shown to be reversible whereas forested areas are being cleared for agricultural use while agricultural areas are also being abandoned and gradually converted to forests at comparably the same rate.

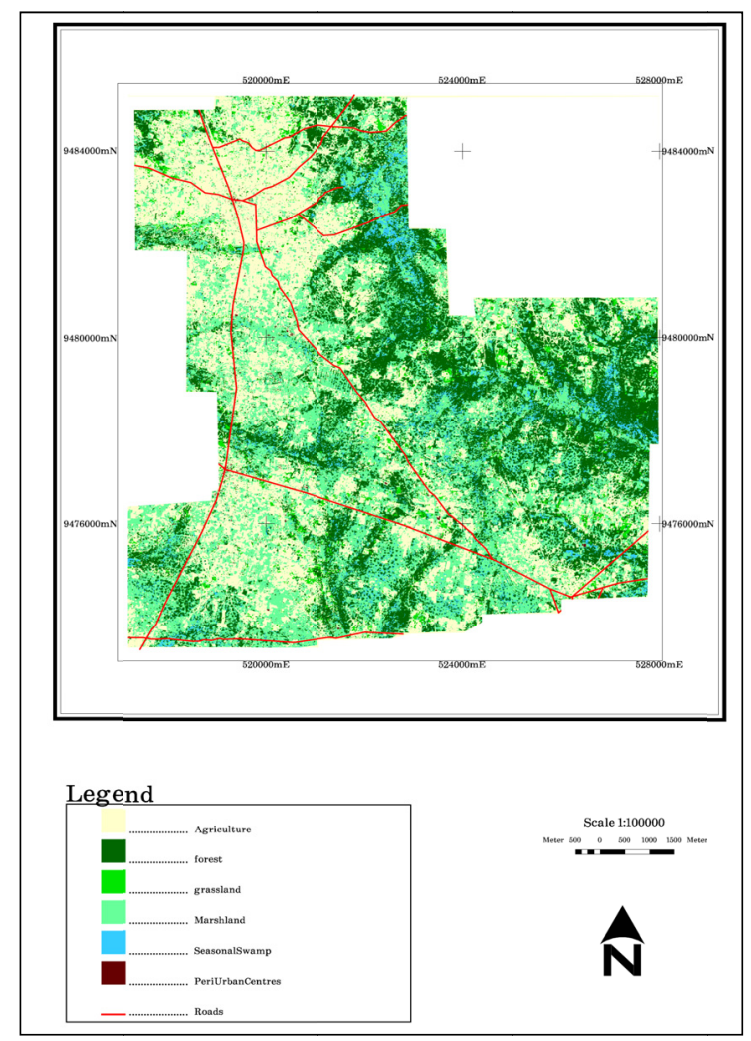

Figure 6. Land use map of Puge division compiled from 2006 IRS satellite imagery

Differences in the characteristics of datasets used could potentially contribute to changes detected in each land use class. To minimize this effect spatial coverage of individual classes were compared for the change period 1978-1986 between aerial photographs and Landsat TM satellite imagery. For the change period 2000-2006 IRS satellite imagery at $5 \mathrm{~m}$ spatial resolution was resampled to $15 \mathrm{~m}$ while Landsat ETM+ satellite image was IHS/RGB transformed using the $15 \mathrm{~m}$ PAN band. The resampled/transformed images were classified, results of which formed input to change detection. On the other hand differences in seasonality of the datasets have contributed to land use changes detected. Having IRS and Landsat ETM+ images acquired during the wet season while Landsat TM image was acquired during the dry season resulted into seasonal changes within individual land use classes. These changes can be minimized by acquiring multitemporal data from the same seasonality i.e. "similar calendar dates" (Srivastava, Han, Rico-Ramirez, Bray, \& Islam, 2012).

\subsubsection{Land Use Changes During 1978-1986 Period}

This period consist of land use changes detected from aerial photographs (1978) and Landsat TM satellite imagery (1986). Land use changes during this period were identified within agricultural areas, forests and grassland since marshland and seasonal swamps were not mapped from aerial photographs. Forests, woodlands 
and shrubs mapped from aerial photographs were merged to forests. Agricultural land is increasing (Table 3) as only $275.83 \mathrm{Ha}$ were identified as agricultural land in 1978 compared to $14217.79 \mathrm{Ha}$ in 1986; a rise of about $65 \%$.

Forest cover had decreased by about 5\% during this period with $79 \%$ of the forested land being maintained as forests by mid 1980s. About $1062 \mathrm{Ha}$ of forests were cleared for agriculture during this period compared to $13066 \mathrm{Ha}$ of grasslands cleared for the same thus the rate of conversion of forests to agricultural use in this period is low.

Table 3. Land use change matrix giving total areas in Hectares of land use maintained/changed within land use classes during $1978-1986$

\begin{tabular}{lllllllll}
\hline Form/To & Agriculture & Forests & Grassland & Marshland & $\begin{array}{l}\text { P } \\
\text { Centres }\end{array}$ & $\begin{array}{l}\text { S } \\
\text { Swamps }\end{array}$ & $\begin{array}{l}\text { Total } \\
\text { (Ha) }\end{array}$ & $\begin{array}{l}\text { Total } \\
(\%)\end{array}$ \\
\hline Agriculture & $\mathbf{8 8 . 6 1}$ & 53.31 & 124.05 & 3.88 & 3.29 & 2.68 & 275.83 & 1.27 \\
Forests & 1062.63 & $\mathbf{3 0 9 6 . 6}$ & 1053.18 & 64.79 & 22.12 & 6.33 & 5305.42 & 24.48 \\
Grassland & 13066.82 & 783.43 & $\mathbf{2 1 1 8 . 4 7}$ & 59.93 & 51.40 & 15.43 & 16095.46 & 74.25 \\
Marshland & N/A & N/A & N/A & N/A & N/A & N/A & 0.00 & 0.00 \\
P Centres & N/A & N/A & N/A & N/A & N/A & N/A & 0.00 & 0.00 \\
S Swamps & N/A & N/A & N/A & N/A & N/A & N/A & 0.00 & 0.00 \\
Total (Ha) & 14217.79 & 3933.39 & 3295.70 & 128.59 & 76.81 & 24.44 & & \\
Total (\%) & 65.59 & 18.15 & 15.20 & 0.59 & 0.39 & 0.11 & & \\
\hline
\end{tabular}

Note: N/A stands for Not Applicable i.e. marshland, P_Centres and S_Swamps were not mapped from Aerial Photographs.

\subsubsection{Land Use Changes During 1986 - 2000 Period}

Land use changes were detected from landsat TM imagery (1986) and Landsat ETM+ imagery (2000). Changes were identified within agricultural areas, forests, grassland, marshland and seasonal swamps. Results are presented by a change matrix (Table 4) and change maps emphasizing changes within agricultural and forested areas (Figures 7 and 8). 


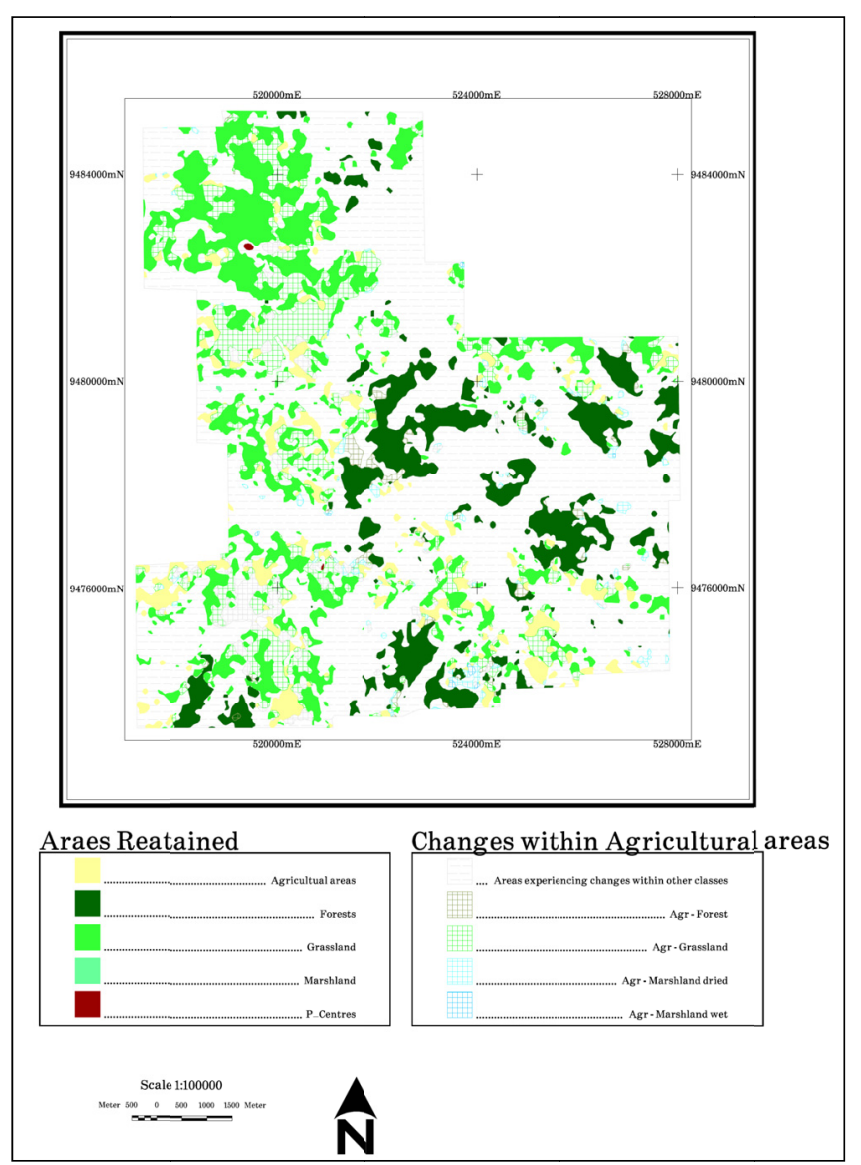

Figure 7. Agricultural areas maintained/changed during 1986-2000 period

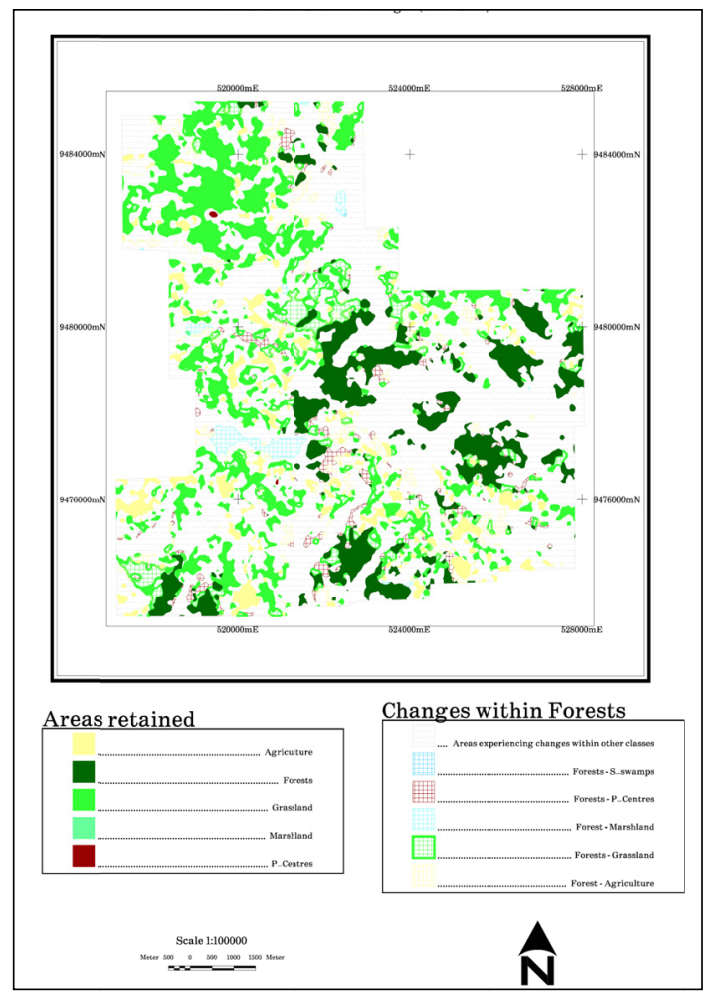

Figure 8. Forested areas maintained/changed during 1986 - 2000 period 
Table 4. Land use change matrix giving total areas in Hectares of land use maintained/changed within land within land use classes during $1986-2000$

\begin{tabular}{lllllllll}
\hline Form/To & Agriculture & Forests & Grassland & Marshland & $\begin{array}{l}\text { P } \\
\text { Centres }\end{array}$ & $\begin{array}{l}\text { S } \\
\text { Swamps }\end{array}$ & $\begin{array}{l}\text { Total } \\
(\text { Ha) }\end{array}$ & $\begin{array}{l}\text { Total } \\
(\%)\end{array}$ \\
\hline Agriculture & $\mathbf{5 0 7 . 4 5}$ & 1496.96 & 1495.50 & 43.09 & 0.00 & 11.18 & 3554.18 & 27.65 \\
Forests & 153.69 & $\mathbf{3 7 1 7 . 6 3}$ & 397.10 & 23.76 & 0.00 & 99.70 & 4391.88 & 34.16 \\
Grassland & 1039.03 & 1465.80 & $\mathbf{2 0 2 7 . 3 9}$ & 70.61 & 4.33 & 3.33 & 4606.49 & 35.83 \\
Marshland & 9.25 & 116.75 & 6.03 & $\mathbf{0 . 4 3}$ & 0.00 & 2.92 & 135.39 & 1.05 \\
P Centres & 14.14 & 69.19 & 55.50 & 2.51 & $\mathbf{1 . 0 7}$ & 2.29 & 139.69 & 1.09 \\
S Swamps & 2.58 & 20.59 & 4.26 & 0.72 & 0.00 & $\mathbf{0 . 0 1}$ & 28.16 & 0.22 \\
Total (Ha) & 1722.14 & 6883.92 & 3985.79 & 141.11 & 5.39 & 117.42 & & \\
Total (\%) & 13.40 & 53.55 & 31.00 & 1.10 & 0.04 & 0.04 & & \\
\hline
\end{tabular}

Agricultural land declined during this period. 3554.18 Ha were detected as agricultural land in 1986 compared to $1722.14 \mathrm{Ha}$ in 2000 a drop of about $14 \%$. Some of the agricultural land was abandoned during this period growing into grasslands.

Forested land acreage is observed to have increased during this period. This is partly because more forests were detected from the Landsat ETM+ satellite imagery (2000) which was acquired during the wet season as compared to those detected from Landsat TM imagery (1986) which was acquired during the dry season. It is also observed that $54 \%$ of the forested area was maintained during this period; decreasing from the $79 \%$ that was maintained during 1978-1986 period. Changes in the forested areas were observed in both directions, some of the forested land was converted to other uses while other uses were also converted to forests. Generally, most of land use changes during this period are in conjunction with agricultural land use which was identified to concentrate along road networks (Figure 3-6). Proximity to road networks is one the major factors facilitating the conversion of forest into agricultural and other uses and conversion of agricultural use into peri-urban settlements.

\subsubsection{Land Use Changes During 2000-2006 Period}

Land use changes were detected from Landsat ETM+ imagery (2000) and IRS satellite imagery (2006). Changes during this period were identified within agricultural areas, forests, grassland, marshland, seasonal swamps and peri-urban centres (Figures 9 and 10). 


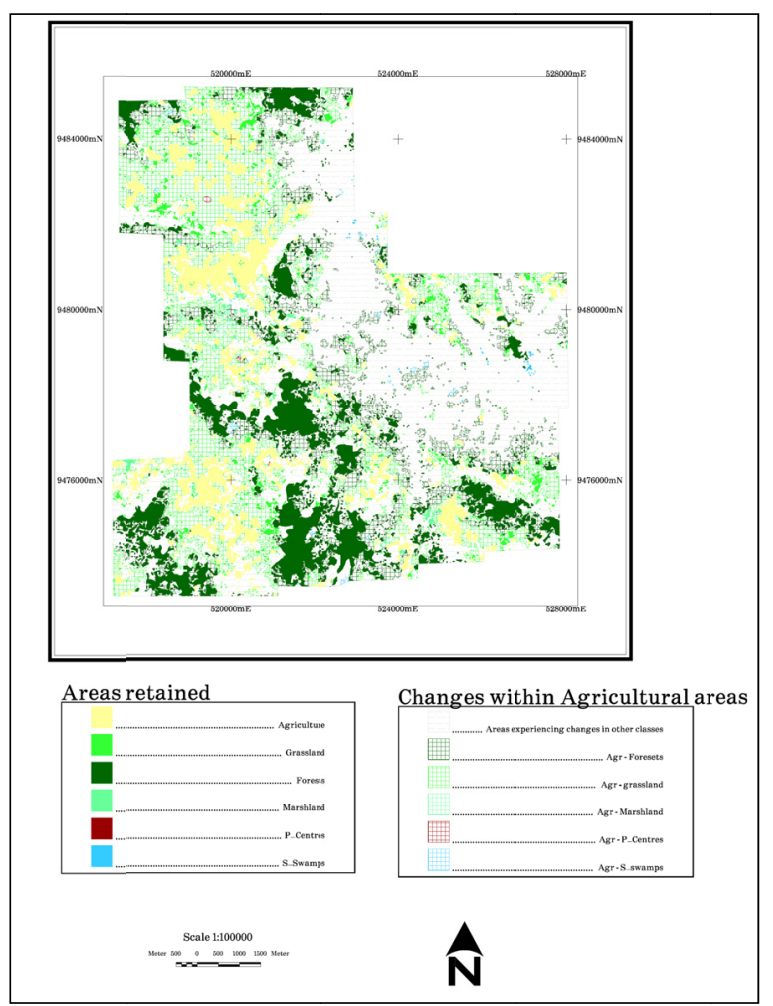

Figure 9. Agricultural areas maintained/changed during 2000 - 2006

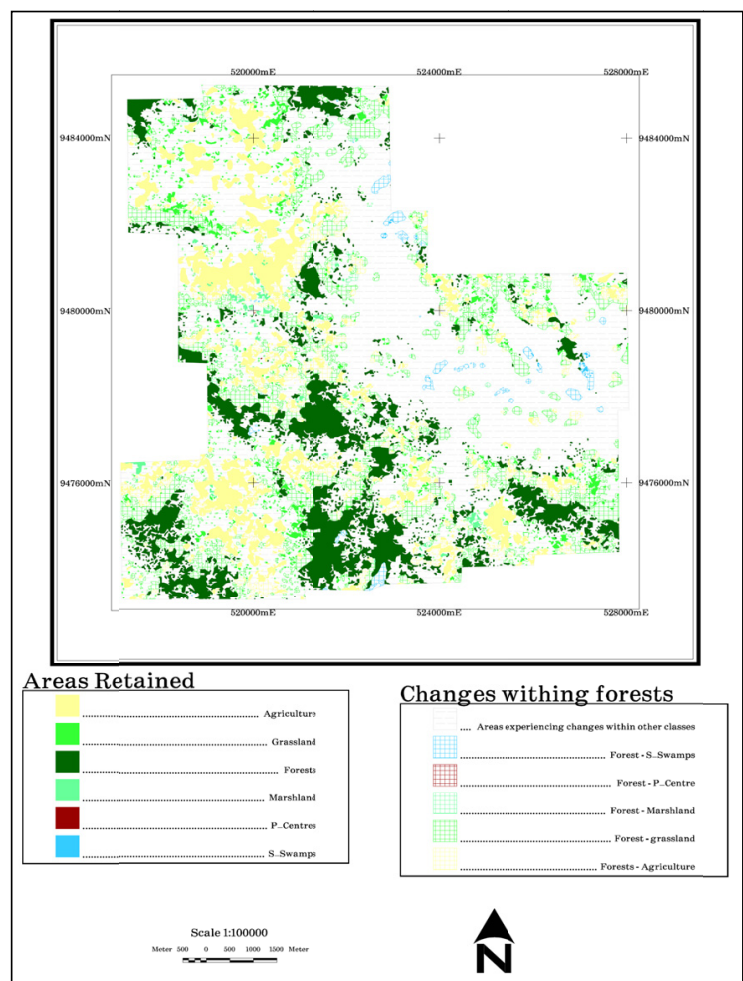

Figure 10. Forested areas maintained/changed during 2000 - 2006 
Table 5. Land use change matrix giving total areas in Hectares of land use maintained/changed within land use classes during 2000 - 2006

\begin{tabular}{ccccccccc}
\hline Form/To & Agriculture & Forests & Grassland & Marshland & $\begin{array}{c}\text { P } \\
\text { Centres }\end{array}$ & $\begin{array}{c}\text { S } \\
\text { Swamps }\end{array}$ & $\begin{array}{c}\text { Total } \\
\text { (Ha) }\end{array}$ & $\begin{array}{c}\text { Total } \\
\text { (\%) }\end{array}$ \\
\hline Agriculture & $\mathbf{9 5 2 . 8 9}$ & 626.82 & 48.16 & 320.20 & 3.10 & 8.27 & 1959.44 & 13.34 \\
Forests & 1909.39 & $\mathbf{4 7 8 4 . 5 3}$ & 200.67 & 1002.72 & 4.21 & 96.78 & 7998.31 & 54.45 \\
Grassland & 2123.83 & 1592.83 & $\mathbf{1 6 1 . 0 6}$ & 522.43 & 4.32 & 19.14 & 4423.61 & 30.12 \\
Marshland & 62.93 & 70.82 & 3.79 & $\mathbf{2 9 . 4 7}$ & 0.11 & 1.14 & 168.26 & 1.15 \\
P Centres & 3.23 & 0.78 & 0.10 & 0.79 & $\mathbf{0 . 0 2}$ & 0.00 & 5.10 & 0.03 \\
S Swamps & 12.91 & 101.75 & 0.38 & 15.65 & 0.00 & $\mathbf{3 . 5 2}$ & 134.21 & 0.91 \\
Total (Ha) & 5065.18 & 7177.53 & 414.16 & 1891.44 & 11.76 & 128.85 & & \\
Total (\%) & 34.48 & 48.86 & 2.82 & 12.88 & 0.08 & 0.88 & & \\
\hline
\end{tabular}

Note: Diagonal elements represent Maintained areas.

Agricultural land has significantly increased during this period. About $5065 \mathrm{Ha}$ were detected as agricultural land in 2006 compared to $1959 \mathrm{Ha}$ in 2000 a rise of about $20 \%$ which is explained by policy implementation as discussed in section 4.1.4. Most of the previously cultivated areas were abandoned to gradually grow into grasslands while new areas were acquired for cultivation. Forests have generally maintained their spatial coverage during this period with about $7998 \mathrm{Ha}$ detected in 2000 and about $7177 \mathrm{Ha}$ in $2006.67 \%$ of the forests were maintained during this period; a rise of 13\% compared to 1986-2000 period. Changes were observed from forest to other uses and from other uses to forest as shown by both the change matrix (Table 5) and the change maps (Figure 8 and 9). Generally, most of the changes in land use during this period are concentrated along road networks thus proximity to road network is still one of the major factors facilitating the conversion from forest into agricultural and other uses and conversion form agricultural uses into peri-urban settlements.

\section{Impacts of Land Use Changes on Agricultural Area}

The major impact of land use changes on an agricultural area identified in this study is the rise of agricultural production. This rise is evident from the yields per farming season where 934 tonns of food and cash crops were produced as surplus during 2005-2006 in Puge South. The increased land acreage occupied by agricultural fields (Tables 3-5) further confirms the rise in agricultural production.

It is noted that the rate of conversion of all land use categories to agricultural land is generally highest among other land use categories in all the three periods of change detection.

\section{Conclusion}

This study was undertaken for the purpose of detecting, mapping and analyzing the conversion of forests into agricultural uses and agricultural uses into urban/peri-urban uses that have taken place in Tabora region for a period of 28 years since 1978 using IRS satellite images. A focus area selected within Tabora region comprised of part of Nzega district to allow a detailed study. To characterize land use and land use changes for the period when IRS satellite images were not available, Landsat TM and Landsat ETM+ satellite images dated 1986 and 2000 respectively, and aerial photographs dated 1978 were used.

The land use classes of particular interest to this study namely agricultural uses and forests were adequately compiled from all the data sets. However, peri-urban centers could only be mapped from IRS satellite images while individual houses were mapped from aerial photographs. The spatial resolution of both Landsat TM and Landsat ETM+ could not facilitate mapping of peri-urban centers or any other settlement patterns present in Nzega District.

Despite the differences in characteristics of data used in this study, land use change maps and land use change matrices were sufficiently and accurately generated from the compiled land use maps. GIS analysis functions (spatial overlay) and image processing functions (IHS/RGB transformation) provided capabilities of blending together data sets with different image resolution to achieve common resolution for comparison purposes.

The results show that an average of about $1042 \mathrm{Ha}$ of forests were converted into agricultural uses during the study period i.e. 1978-2006 while an average of $3 \mathrm{Ha}$ of agricultural uses were converted to peri-urban uses in the same period. The rate of conversion of forests into agricultural areas is low compared to that of grasslands, 
thus grasslands help to minimize and control forest clearance for agricultural uses. Moreover the rate of conversion of agricultural land to peri-urban centers was low compared to what was anticipated i.e. high conversion rate as a result of rapid urban/peri-urban growth to accommodate growing population. This was observed to be a result of the mixed farming practices of the area of study and poor infrastructure development retarding the growth from conventional to technologically advanced farming practices which could facilitate peri-urban/urban growth. Non agricultural land was converted to agricultural land at a relatively high rate compared to the conversion of agricultural land into non agricultural land uses.

The proximity of agricultural areas to roads, forests and grassland facilitated its increase in spatial coverage. Most of the agricultural land is concentrated along road networks where by people tend to expand their farms by acquiring adjacent unoccupied land. This implies that agricultural uses decrease with increased distance from road networks while forests on the other hand increase with increased distance from road networks. Similar results were found by Patarasuk and Binford (2012). Forests in most cases are adjacent to grassland which helps minimizing forest clearance for agricultural use.

It is important to acquire an in depth understanding of processes leading to land use changes so as to be able to monitor and manage changes occurring within small spatial extents and further to be able to manage natural resources including arable land for agricultural purposes. This study provides a starting point for improved mapping of land use changes in Tabora region and Tanzania at large.

\section{References}

Amani, H. K. R. (2005). Agricultural development and food security in sub-Saharan Africa Tanzania Country report. Economic and Social Research Foundation (ESRF) Dar es Salaam, Tanzania. Retrieved from http://www.fao.org/tc.TCA/work05/Tanzaniappt.ppt\#256.1

Briassoulis, H. (2000). Analysis of Land Use Change: Theoretical and Modeling Approaches. Regional Research institute, West Viginia University.

FOSA - Forest Outlook Studies in Africa. (2000). FOSA country report - Tanzania. Retrieved June 26, 2007, from http://www.fao.org/DOCREP/003/AB575E/AB575E00.htm\#TOC

Hubacek, K., \& Sun, L. (2001). A scenario analysis of China's land use and land cover change: incorporating biophysical information into input modeling. Elsevier Structural change and economic dynamics. http://dx.doi.org/10.1016/S0954-349X(01)00029-7

Kalenzi D. Personal Communication, (13 ${ }^{\text {th }}$ October, 2006). Head of section, Physical planning and research, National Land Use Planning Commission. Dar es salaam.

Kanddrika, S., \& Roy, P. S. (2008). Land use land cover classification of Orissa using multi-temporal IRS-P6 awifs data: A decision tree approach. International Journal of Applied Earth Observation and Geoinformation, 10, 186-193. http://dx.doi.org/10.1016/j.jag.2007.10.003

Lambin, E. F., Geist, H. J., \& Lepers, E. (2003). Dynamics of land-use land-cover change in tropical regions. $\begin{array}{llll}\text { Annual Reviews } & \text { Environmental 285-241. }\end{array}$ http://dx.doi.org/10.1146/annurev.energy.28.050302.105459

Lillesand, T. M., Kiefer, R. W., \& Chipman, J. W. (2004). Remote sensing and Image Interpretation (5th ed.). New York, USA: John Wiley and sons, Inc.

Mather, P. M. (1999). Computer Processing of Remotely-Sensed Images. Joh wiley \& Sons Ltd. England.

Mbwambo, L. (2004). Status of arid and semi arid lands of Tanzania. A paper presented at the Drylands Agroforestry Workshop, $1^{\text {st }}-3^{\text {rd }}$ September, 2004, ICRAF Headquarters, Nairobi Kenya.

Mertens, B., \& Lambin, E. (1999). Modeling land cover dynamics: Integration of fine scale land cover data with landscape attributes. International Journal of Applied Earth Observation and Geoinformation, 1(1), 48-52. http://dx.doi.org/10.1016/S0303-2434(99)85027-2

Patarasuk, R., \& Binford, M. W. (2012). Longitudinal analysis of the road network development and land-cover change in Lop Buri province, Thaniland, 1989-2006. Applied Geography, 32, 228-239. http://dx.doi.org/10.1016/j.apgeog.2011.05.009

Srivastava, P. K., Han, D., Rico-Ramirez, M. A., Bray, M., \& Islam, T. (2012). Selection of classification techniques for land use/cover change investigation. Advances in Space Research, 50, 1250-1265. http://dx.doi.org/10.1016/j.asr.2012.06.032

TRIDEP. (1980). AERIAL Survey of Natural Resources. Final Report. Ecosystems Limited Nairobi. Kenya. 
Tunner, B. L., Moss, R. H., \& Skole, D. L. (1993). Relation Land use and global land cover change. Joint publication of the International Geosphere-Biophere Programme (Report N.24) and the Human Dimensions of Global Environmental Change Programme (Report No. 5). Stockholm: Royal Swedish Academy of Sciences. Retrieved October 10, 2006, from www.ciesin.org/docs/002-105/002-105.html

Wikipedia. (2006). The free encyclopedia. Tabora region.

Xiaojian, L., Jim, P., Gang-Jung, L., \& Lexiang, Q. (2000). Assessing regional sustainability: the case of land use and land cover change in the middle Yiluo catchment of the Yellow River basin, china. Pergamon applied Geography.

\section{Copyrights}

Copyright for this article is retained by the author(s), with first publication rights granted to the journal.

This is an open-access article distributed under the terms and conditions of the Creative Commons Attribution license (http://creativecommons.org/licenses/by/3.0/). 